\title{
Risk assessment of oil and gas producing areas in Siberia
}

\author{
A. Lepikhin \& V. Moscvichev \\ Department of Safety Engineering Systems, \\ SDTB "Nauka" KSC SB RAS, Russia
}

\begin{abstract}
This article considers the research results of anthropogenic risks that are stipulated by the development of oil and gas producing areas in Siberia. It contains a brief description of the background status of natural environment in these areas. In addition, the models and criteria of anthropogenic risk assessment are determined. This paper presents the estimates of technological (permanent) risk and risk of accidents. Anthropogenic risk maps for oil and gas producing areas of the Krasnoyarsk region are developed.

Keywords: anthropogenic risk, models, contamination, gas and oil producing area.
\end{abstract}

\section{Introduction}

The Russian Federation is one of the largest oil and gas producing countries in the world. Nowadays the most intensive development is connected with new deposits in Siberia and the Far North. These deposits are located in difficult geographical and climatic conditions. Most of them are situated in the areas with unique ecological systems. Therefore, engineering infrastructure of such deposits is the subject to special security requirements.

Economic, environmental and social risks are the comprehensive measures of the incipient anthropogenic threats for oil and gas producing areas. The problem the risk analysis for oil and gas facilities was consider in the works [1-3]. This paper presents the concept and the results of risk analysis for oil and gas producing areas in the Krasnoyarsk region of Siberia. The main feature of this concept lies in the object of study - distributed natural-and-industrial system. This system includes engineering infrastructure of oil and gas deposits that 
interacts with the natural environment. The subjects of this study are typical risk factors: air pollution, water pollution, soil pollution, degradation of plant and animal life.

\section{The concept of risk analysis}

Special object of research impose a number of specific requirements to risk analysis. This analysis should be based on the principles of complexity, regularity, field investigations and automatic data processing. Complexity means the status assessment of all the environment components of oil and gas producing areas. Regularity implies a continuous receiving the information about the engineering infrastructure objects and the natural environment from the stage of design and exploration work to the stage of well abandonment. Field investigations are determined by the distribution of engineering infrastructure in oil and gas producing areas. The number of environment monitoring methods for such distributed systems is seriously limited. The most preferable method is the aerospace monitoring [4]. The large number of controlled parameters and the high level of their variability in time and space define necessity of the automatic data processing. The scheme of risk analysis based on the principles mentioned is presented in Figure 1.

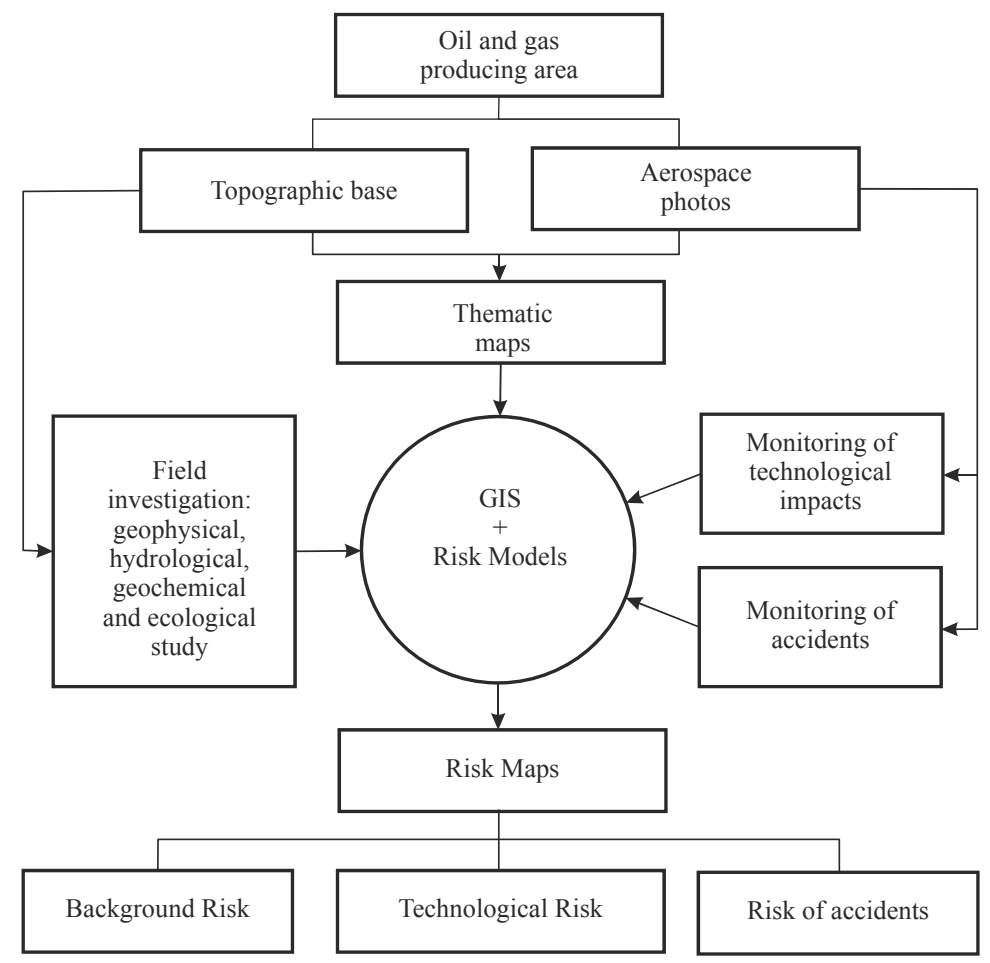

Figure 1: $\quad$ The scheme of risk analysis and risk mapping. 
The concept of risk analysis under consideration is based on the information about oil and gas infrastructure facilities in the form of thematic maps $[5,6]$. This database also contains estimates of the natural environment conditions, data on technological impact and accidents. This information may be obtained by means of aerospace monitoring, geodesic, geophysical, hydrological, geochemical, ecological and other observations and studies. Aerospace monitoring makes it possible to present oil and gas production facilities in the form of linear, matrix and raster models. Two-dimensional description of facilities in the form of coordinate assignment of control points can be used for risk analysis.

Risk models compose the core of this concept. These models include three types of risk: the background risk, the technological risk and the risk of accidents.

Taking this into account, we can do information analysis, risk identification, risk assessment and risk mapping by means of GIS technology. Risk maps allow conducting the comparative assessment of areas under the risk and the development of corrective actions that reduce risk. Ultimately, this concept provides the transition from the passive model of monitoring threats to the active model of status management for oil and gas producing areas. Risk assessment in this scheme ensures the correspondence between the developed corrective actions and the scale of the threat.

\section{Models and methods of anthropogenic risk assessment}

Formally, anthropogenic risk can be presented as a function of the probability of man-made or natural-and-man-made adverse events with coincident damages. In general, anthropogenic risk for the area $\mathrm{S}$ can be presented in the following form [7]:

$$
R(S)=\sum_{i=1}^{n} \sum_{j=1}^{m} \sum_{k=1}^{l} \int_{S} P_{i j k}(S) V_{i j k}(S) U_{i j k}(S) d S
$$

where $n, m, l$ - the numbers of possible emergency situations of natural, manmade, natural-and-man-made origin; $P_{i j k}(S)$ - the probability of disaster; $V_{i j k}(S)$ the probability of natural environment, population and infrastructure demolition in case of emergency situation; $U_{i j k}(S)$ - the damages and losses from the disaster.

The probability of emergencies is not the only argument of anthropogenic risk function. This risk also depends on the vulnerability, survivability and security of oil and gas producing areas. Thus, the risk assessment formula can be presented as follows [8]:

$$
R(S, t)=\sum_{j} P_{j} v_{j} \gamma_{j} z_{j} U_{j}(S) ; j=1, N ; 0<\gamma, z \leq 1 ; v \geq 1,
$$

where $N$ - the number of risk factors that influence the area $S ; P$ - the probability of hazardous impact; $v, \gamma, z$ - the vulnerability, survivability and security indices; $U$ - the possible (direct and indirect) damages and losses. 
Vulnerability is a parameter that shows the sensitivity of an object or a territory to the impact of a risk factor or a group of risk factors. Survivability describes the ability of the industrial, natural and social system to perform the basic functions after damage. Security is defined by the resource endowment of the system that allows reacting against the internal and external threats as well as isolating and liquidating the possible damages and losses.

The implementation of the mentioned anthropogenic risk models requires a large amount of information about the nature of anthropogenic threats, pollutants and their concentration in the atmosphere, soil, water of oil and gas producing areas. For instance, the trends of pollutant accumulation cannot be defined due to small database of observations on man's impact for oil and gas producing areas. However, it can be done by means of asymptotic estimates of the accumulated contamination levels. Since the safety level of contamination is unknown, the first approximation of such estimates may be based on risk-threshold model of pollutants. In this case, the risk model of anthropogenic contamination can be presented in the following form:

$$
R_{e}(t)=1-\exp \left\{-\alpha \vartheta^{\beta}\right\}
$$

where $\vartheta=\mathrm{C} / \mathrm{MPC}$ - the relative concentration of pollutant that operates for a period of time $t ; \alpha$ - the index that connects the risk and the concentration of pollutant; $\beta$ - the index that considers the danger of pollutant to the environment; $\mathrm{C}$ - the concentration of pollutant; MPC - the maximum permissible concentration of pollutant.

The parameters $\alpha$ and $\beta$ are determined simply by the pollutant danger to the ecosystems of oil and gas producing areas considering vulnerability, survivability and security indices.

\section{The results of anthropogenic risk assessment}

Figure 2 shows the location of oil and gas producing areas in the Krasnoyarsk region. Deposits and engineering facilities are located within the territory of Taimyr, Turukhansk and Evenki municipal districts. Evaluation of vulnerability, survivability and security indices $(v, \gamma, z)$ for these areas is a complicated task that requires an integrated approach and in-depth analysis of the areas. These indices were derived from the generalized expert estimates for the major oil and gas producing areas of the Krasnoyarsk region (table 1).

The risk assessment results for oil and gas producing areas of the Krasnoyarsk region received in accordance with the equation 3 are presented in tables 2 and 3. Table 4 shows the results of risk assessment according to the maximum permissible concentration of pollutants for the considered areas. The calculation was performed for such pollutants as sulfur dioxide, soot, carbon monoxide, saturated hydrocarbons (C1-C19). 
Table 1: $\quad$ Vulnerability, survivability and security indices.

\begin{tabular}{|l|c|c|c|}
\hline \multirow{2}{*}{ Index } & \multicolumn{3}{|c|}{ Area } \\
\cline { 2 - 4 } & Vankor & Yurubcheno-Tahomsky & Kuyumbinsky \\
\hline Vulnerability, $v$ & 1.2 & 1.1 & 1.05 \\
\hline Survivability, $\gamma$ & 0.6 & 0.8 & 0.9 \\
\hline Security, $z$ & 0.4 & 0.6 & 0.7 \\
\hline
\end{tabular}

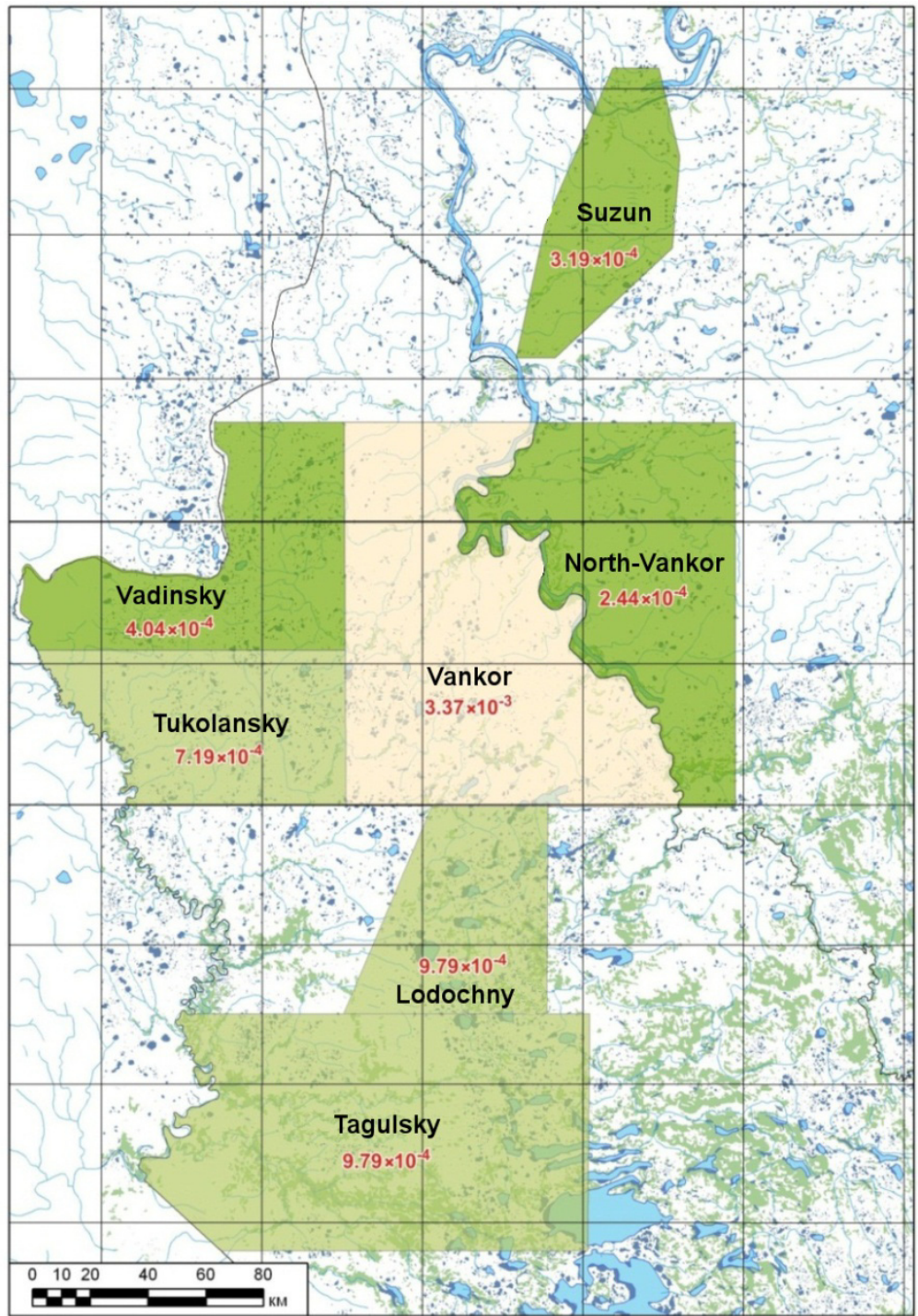

Figure 2: Risk of oil and gas producing areas in the north of the Krasnoyarsk region according to the maximum concentration of pollutants. 
Table 2: $\quad$ Technological (permanent) risk of water contamination.

\begin{tabular}{|c|c|c|c|}
\hline \multirow{2}{*}{ Pollutant } & \multicolumn{3}{|c|}{ Area } \\
\hline & Vankor & Yurubcheno-Tahomsky & Kuyumbinsky \\
\hline Sulphate & $9.37 \times 10^{-5}$ & $8.61 \times 10^{-3}$ & $5.91 \times 10^{-3}$ \\
\hline Chloride & $7.63 \times 10^{-5}$ & $1.42 \times 10^{-4}$ & $1.59 \times 10^{-3}$ \\
\hline $\begin{array}{l}\text { Chemical oxygen } \\
\text { demand ( COD) }\end{array}$ & 0.26 & 0.09 & 0.16 \\
\hline $\begin{array}{l}\text { Synthetic surface- } \\
\text { active agents (SPP) }\end{array}$ & $4.99 \times 10^{-5}$ & $1.26 \times 10^{-3}$ & $1.26 \times 10^{-3}$ \\
\hline Oil products & $7.96 \times 10^{-5}$ & $2.10 \times 10^{-3}$ & $1.00 \times 10^{-2}$ \\
\hline
\end{tabular}

Table 3: $\quad$ Technological (permanent) risk of soil contamination.

\begin{tabular}{|l|c|c|c|}
\hline \multirow{2}{*}{ Pollutant } & \multicolumn{3}{|c|}{ Area } \\
\cline { 2 - 4 } & Vankor & Yurubcheno-Tahomsky & Kuyumbinsky \\
\hline Lead & $8.02 \times 10^{-4}$ & $4.04 \times 10^{-3}$ & $6.88 \times 10^{-4}$ \\
\hline Arsenic & 0.09 & 0.095 & 0.023 \\
\hline Mercury & $1.81 \times 10^{-5}$ & $1.93 \times 10^{-4}$ & $1.46 \times 10^{-4}$ \\
\hline Oil products & $3.9 \times 10^{-2}$ & $2.5 \times 10^{-2}$ & $2.3 \times 10^{-2}$ \\
\hline
\end{tabular}

Table 4: $\quad$ Risk according to the maximum concentration of pollutants.

\begin{tabular}{|c|l|c|c|}
\hline $\mathrm{N}$ & \multicolumn{1}{|c|}{ Area } & $\begin{array}{c}\text { Concentration of } \\
\text { pollutants, } \vartheta=\mathrm{C} / \mathrm{MPC}\end{array}$ & Risk \\
\hline 1 & Vankor & 0.26 & $3.37 \times 10^{-3}$ \\
\hline 2 & Agaleevskaya & 0.17 & $2.79 \times 10^{-3}$ \\
\hline 3 & Tagulsky & 0.14 & $9.79 \times 10^{-4}$ \\
\hline 4 & Yurubchensky & 0.63 & $1.90 \times 10^{-2}$ \\
\hline 5 & Kuyumbinsky & 0.16 & $2.55 \times 10^{-3}$ \\
\hline 6 & Sobinsky & 0.2 & $3.57 \times 10^{-3}$ \\
\hline 8 & Tersko-Kamovsky & 0.1 & $1.26 \times 10^{-3}$ \\
\hline 9 & Omorinsky & 0.0009 & $1.08 \times 10^{-6}$ \\
\hline 10 & Beryambinsky & 0.1 & $1.26 \times 10^{-3}$ \\
\hline 31 & Lodochny & 0.14 & $9.79 \times 10^{-4}$ \\
\hline 36 & Chulakansky & 0.16 & $2.55 \times 10^{-3}$ \\
\hline 38 & Payginsky & 0.14 & $2.09 \times 10^{-3}$ \\
\hline 39 & Kordinsky & 0.26 & $5.28 \times 10^{-3}$ \\
\hline 40 & Baykit & 0.09 & $1.07 \times 10^{-3}$ \\
\hline 45 & Vadinsky & 0.09 & $4.04 \times 10^{-4}$ \\
\hline 46 & Tukolansky & 0.12 & $7.19 \times 10^{-4}$ \\
\hline 73 & Suzun & 0.08 & $3.19 \times 10^{-4}$ \\
\hline 74 & North-Vankor & 0.07 & $2.44 \times 10^{-4}$ \\
\hline
\end{tabular}

The estimates show a relatively high risk of ecosystem degradation for the following oil and gas producing areas: Sobinsky, Vankor, Kordinsky, Yurubchensky. Due to small statistical database on the contamination, these 
estimates should be considered as comparative and related not only to anthropogenic effects of oil and gas production, but also to the effects from the area urbanization.

\section{Maps of anthropogenic risk}

Overview maps of anthropogenic risks for oil and gas producing areas of the Krasnoyarsk region were developed using a combination of thematic layers and topographic multi-scale layers. Thematic layers are presented in the projection WGS1984, overview maps of areas and thematic maps of risks are presented in the projection Gauss Kruger Pulkovo 1942 Zone 16. Overview maps of anthropogenic risk for oil and gas industry of the Krasnoyarsk region were developed based on technological features and professional systems like ArcGIS 9.3 and MapInfo9. These maps were designed for risks of accumulated concentrations and maximum concentrations of pollutants.

Figures 2 and 3 show the examples of risk maps for oil and gas producing areas according to the maximum concentration of pollutants. They show the averaged estimates of risk for these areas. Anthropogenic load inside these areas is distributed irregularly. The areas can be divided into 3 zones with high, medium and moderate risks. High risks occur near oil and gas producing objects $\left(10^{-3}\right.$ or higher) and along the pipelines $\left(10^{-4}\right.$ or higher).

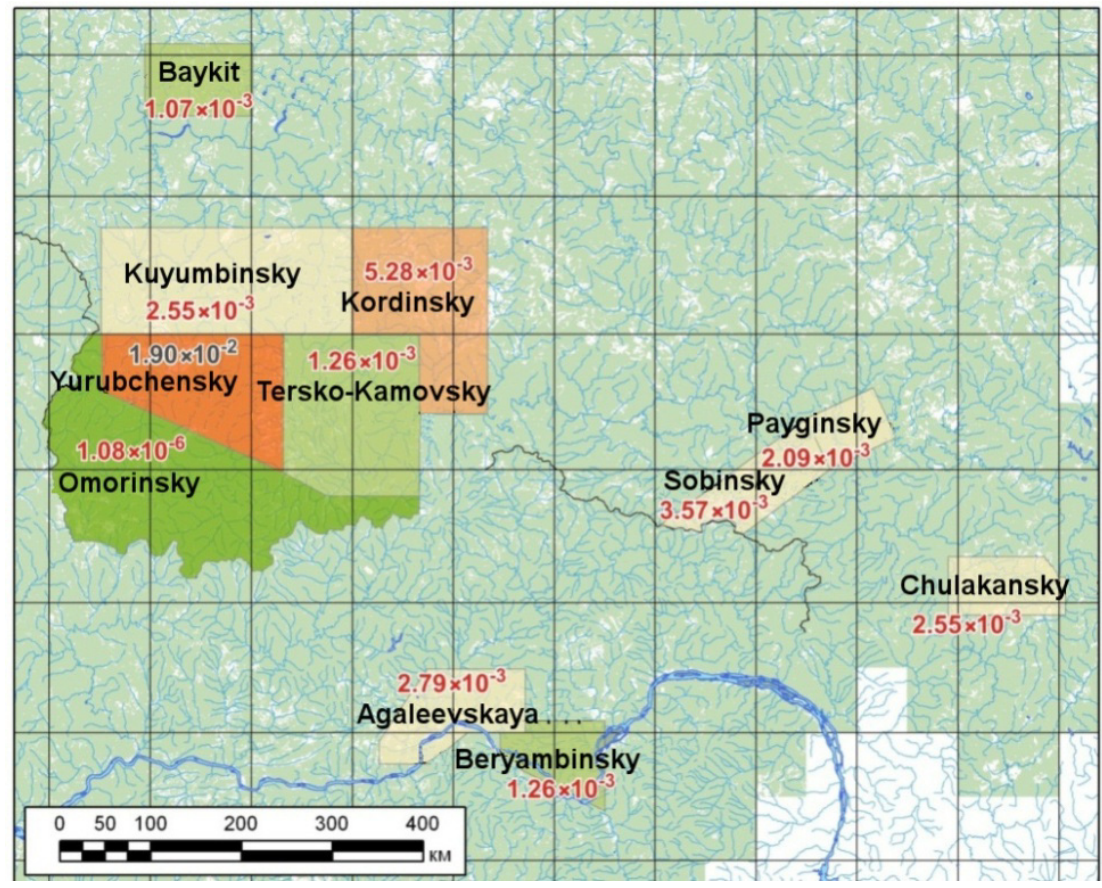

Figure 3: Risk of oil and gas producing areas in Evenki and Lower Angara regions according to the maximum concentration of pollutants. 
Currently, according to the developed technologies of evaluation and mapping a new research book "The Album of anthropogenic risks of Siberia" is being formed. This album will include maps of anthropogenic and natural risks for various components of threats; environmental maps; maps of hazardous objects accommodation and other information.

\section{Conclusion}

Development and urbanization of the northern territories with unique ecological systems requires special attention to the risk assessment. Here the classical approach of acceptable risk level establishment is not sufficient because any risk may lead to irreversible consequences for the unique natural environment. For this reason, it is essential to develop an effective strategy for anthropogenic risks monitoring that minimizes man's impact from oil and gas facilities on the environment. The proposed concept of risk analysis based on field data and the results of aerospace monitoring of oil and gas-producing areas can solve this problem.

The obtained results of risk assessment indicate a relatively low level of anthropogenic threats for the territories under discussion. However, these risks can significantly increase due to the oil and gas production development. Therefore, the expansion of oil and gas production should be accompanied by the development of appropriate corrective actions aimed to reduce anthropogenic threats and ensure sustainability of natural ecosystems.

\section{References}

[1] Safety of Russia. Risk analysis and security problems. In 4 parts. Part 3. Applied problems of risk analysis of critical facilities. Moskow. ZNANIE, 2007. - $816 \mathrm{p}$.

[2] Vorobev U., Akimov V., Sokolov U. Prevention and liquidation of emergency oil outflows. - Moskow. In-oktavo, 2005. - 368 p.

[3] Glebova E. Accident risk assessment for the oil and gas facilities, taking into account the human operator error // Oil and Gas Business. - 2008. - V.6. N.2. - P.127-130.

[4] Akovetskiy V. Aerospace monitoring of oil and gas fields. - Moskow. Nedra-Business, 2008. - 454 p.

[5] Shokin U., Moscvichev V., Nicheporchuk V. Methods of anthropogenic risk assessment and risk maps development using GIS // Computational technologies, 2010. - N1. - P. 120-131.

[6] Shokin U., Moscvichev V., Nogenkova L., Nicheporchuk V. Crisis database for management of territorial risks // Computational technologies, 2010. N1. - P. 120-131.

[7] Lepikhin A. Integrated assessment of territorial safety// Safety and emergency problems, 2008. - N5. - P. 93-98.

[8] Lepikhin A. A Critical Look at Risk Analysis of Disasters. Risk Analysis VII \& Brownfields V. WITpress, pp. PI-59-PI-67, 2010. 